\title{
Risk factors of emergency reoperations
}

Received August 7, 2019

Revised October 10, 2019

Accepted October 10, 2019

\section{Corresponding author}

Jun Rho Yoon, M.D.

Department of Anesthesiology and Pain Medicine, Bucheon St. Mary's

Hospital, College of Medicine, The

Catholic University of Korea, 327

Sosa-ro, Wonmi-gu, Bucheon 14647, Korea

Tel: 82-32-340-7075

Fax: 82-32-340-2255

E-mail: pauly@catholic.ac.kr

\section{Tae Kwan Kim, Jun Rho Yoon, Yu Na Choi, Ui Jin Park, Kyoung Rim Kim, and Taehee Kim}

Department of Anesthesiology and Pain Medicine, Bucheon St. Mary's Hospital, College of Medicine, The Catholic University of Korea, Bucheon, Korea
Background: Emergency reoperation is considered to be a quality indicator in surgery. We analyzed the risk factors for emergency reoperations.

Methods: Patients who underwent emergency operations from January 1, 2017, to December 31, 2017, at our hospital were reviewed in this retrospective study. Multivariate logistic regression was performed for the perioperative risk factors for emergency reoperation.

Results: A total of 1,481 patients underwent emergency operations during the study period. Among them, 79 patients received emergency reoperations. The variables related to emergency reoperation included surgeries involving intracranial and intraoral lesions, highest mean arterial pressure $\geq 110 \mathrm{mmHg}$, highest heart rate $\geq 100$ beats/min, anemia, duration of operation > $120 \mathrm{~min}$, and arrival from the intensive care unit (ICU).

Conclusions: The type of surgery, hemodynamics, hemoglobin values, the duration of surgery, and arrival from ICU were associated with emergency reoperations.

Keywords: Anesthesia; Emergency operation; Emergency reoperation; Risk factors.

\section{INTRODUCTION}

Complications after surgical procedures are frequently associated with poor outcomes and high costs [1]. Thus, it is imperative to do everything possible to minimize the chance of complications. However, in the case of fatal complications, the prompt diagnosis of complications and emergency intervention via reoperation may prevent the increased risk and even save lives [2]. Therefore, emergency reoperations following complicated surgeries are known as "final-choice operations" [2,3]. In spite of early diagnoses and therapeutic progress, the mortality rates following emergency reoperation are still high [2,4].

Emergency reoperation is an important index of quality indicators in healthcare institutions $[3,5]$.

However, reports of emergency reoperations tend to be infrequent, brief, and fragmented [3] because they are sometimes considered to be a failure of the primary opera- tion and there is a tendency to refrain from reporting such cases [6]. Furthermore, previous studies have focused on emergency reoperations carried out by individual surgical specialties. Few reoperations have been studied extensively from an anesthesiologist's perspective. The general physical condition of the patient is not as good as anticipated during the recovery period from the previous operation [1] and the intraoperative characteristics would also be different from the other operation. Therefore, we analyzed the risk factors of emergency reoperation from an anesthesiologist's perspective in this study.

\section{MATERIALS AND METHODS}

After receiving Institutional Review Board approval (no. HIRB-2019-0717-070), we retrospectively analyzed all consecutive patients aged $\geq 16$ years who underwent emergency operations from January 1, 2017, to December 31, 2017 (Fig. 1).

This is an Open Access article distributed under the terms of the Creative Commons Attribution Non-Commercial License (http://creativecommons.org/licenses/by-nc/4.0) which permits unrestricted non-commercial use, distribution, and reproduction in any medium, provided the original work is properly cited.

Copyright (C) the Korean Society of Anesthesiologists, 2020 
Emergency reoperation was defined as any unscheduled surgery after the initial operation within the postoperative 60 days $[3,6]$. Interventional radiology procedures conducted in collaboration with anesthesiologists, such as coiling and stenting, were also included. The following data were collected from the electronic medical record database; sex; age; American Society of Anesthesiology classification; medical specialties; the operative lesion; the complexity of the surgery, categorized as minor, moderate, major, and major + blood loss of $\leq 100$, 101-500, 501-999, or 1,000 ml [7-9]; hemodynamic values; hemoglobin (Hgb) and hematocrit values; the anesthetic method and main anesthetic agents; the duration of anesthesia; the net fluid balance; blood transfusions; the use of inotropics; patient-controlled analgesia (PCA); the time the operation commenced, and hospital places of origin and destination. We excluded operations due to unrelated pathology that occurred during the period of recovery from the first operation.

The cases were divided into Group O (emergency operations without a previous operation) and Group R (emer-

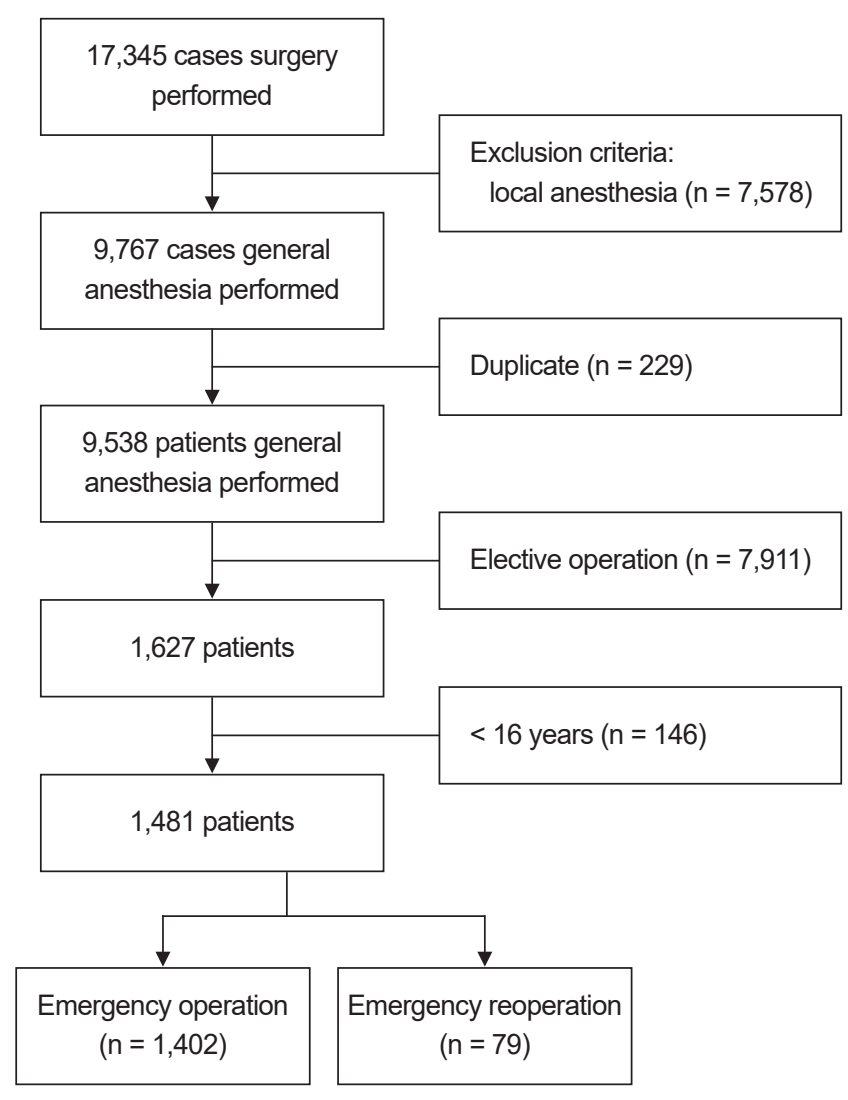

Fig. 1. Flow diagram of patient selection process for this study. Any patient who has received multiple operations is counted as one patient and his or her last operation is selected. gency reoperations following a previous operation within 60 days). Age was categorized as patients older or younger than 65 years. The medical specialties included general surgery, orthopedic surgery, neurosurgery, and others. The operative lesions were grouped into intracranial, intraoral, cervical, intrathoracic, intra-abdominal, and other categories. Abnormal pre-induction blood pressure and heart rate were categorized as pre-induction systolic blood pressure (SBP) $\geq 180 \mathrm{mmHg}$, pre-induction mean arterial pressure (MAP) $\geq 110 \mathrm{mmHg}$, and pre-induction heart rate $(\mathrm{HR})<40$ or $\geq 100$ beats $/ \mathrm{min}$. Based on abnormality in the highest SBP, MAP, and HR during the operation, the patients were categorized as follows: SBP $\geq$ $180 \mathrm{mmHg}$, MAP $\geq 110 \mathrm{mmHg}$, and HR $\geq 100$ beats $/ \mathrm{min}$. Based on abnormality in the lowest SBP, MAP, and HR values during surgery, the following categories were created: SBP $\leq$ $80 \mathrm{mmHg}$, MAP $\leq 60 \mathrm{mmHg}$, and $\mathrm{HR} \leq 40 \mathrm{beats} / \mathrm{min}$. Anemia was defined by Hgb levels $<13 \mathrm{~g} / \mathrm{dl}$ and $<40 \%$ in males and $<12 \mathrm{~g} / \mathrm{dl}$ and $<36 \%$, respectively, in females according to our laboratory guidelines. The duration of anesthesia was categorized as $\leq 120 \mathrm{~min}$ or longer. Based on the time surgery commenced, the surgeries were categorized as regular working time (from 8:00 am to 5:00 pm) on weekdays or non-holidays and outside of working time. Postoperative mortality was defined as death within 30 days postoperatively [9].

The data are expressed as frequencies (\%) and median (range), as appropriate for comparison between the groups. The chi-squared test or Fisher's exact test was used for categorical variables and the Wilcoxon rank-sum test was applied for continuous variables. Univariate and multivariate logistic regression analysis was used to identify the independent predictors of emergency reoperation. A multivariate logistic regression model was constructed using stepwise selection with entry criteria of $\mathrm{P}<0.1$ and significant criteria of $\mathrm{P}<0.05$. We applied Firth's penalized maximum likelihood estimation to reduce bias in the parameter estimates in the multivariate analyses with few events, leading to non-estimable coefficients or 95\% confidence intervals. A P value of $<0.05$ was statistically considered significant. All statistical analyses were performed using SAS software ver. 9.4 (SAS Institute Inc., USA).

\section{RESULTS}

During the study period, 1,481 emergency operations were performed with anesthesiologist involvement (Fig. 1). Comparisons of the baseline demographic characteristics between Group $\mathrm{O}$ and Group R are summarized in Table 1. 
Table 1. Patient Characteristics

\begin{tabular}{|c|c|c|c|c|}
\hline Variable & Overall $(n=1,481)$ & Group $O(n=1,402)$ & Group R $(n=79)$ & $P$ value \\
\hline Sex & & & & 0.582 \\
\hline Male & $668(45.1)$ & $630(44.9)$ & $38(48.1)$ & \\
\hline Female & $813(54.9)$ & $772(55.1)$ & 41 (51.9) & \\
\hline Age (yr) & $51.0 \pm 19.2$ & $51.0 \pm 19.0$ & $57.0 \pm 19.0$ & 0.004 \\
\hline$<65$ & $1,069(72.2)$ & $1,026(73.2)$ & $43(54.4)$ & $<0.001$ \\
\hline$\geq 65$ & $412(27.8)$ & $376(26.8)$ & $36(45.6)$ & \\
\hline ASA & & & & $<0.001$ \\
\hline $1-2$ & $1,100(74.3)$ & $1,068(76.2)$ & $32(40.5)$ & \\
\hline $3-6$ & 381 (25.7) & 334 (23.8) & 47 (59.5) & \\
\hline Operator & & & & $<0.001$ \\
\hline General surgery & $612(41.3)$ & $599(42.7)$ & $13(16.5)$ & \\
\hline Orthopedic surgery & $283(19.1)$ & $276(19.7)$ & 7 (8.9) & \\
\hline Neurosurgery & $224(15.1)$ & $188(13.4)$ & $36(45.6)$ & \\
\hline Others & $362(24.4)$ & $339(24.2)$ & $23(29.1)$ & \\
\hline Lesion & & & & $<0.001$ \\
\hline Intracranial & 221(14.9) & $186(13.3)$ & 35 (44.3) & \\
\hline Intraoral & $10(0.7)$ & $4(0.3)$ & $6(7.6)$ & \\
\hline Cervical & $22(1.5)$ & $15(1.1)$ & $7(8.9)$ & \\
\hline Intrathoracic & 31 (2.1) & $31(2.2)$ & $0(0.0)$ & \\
\hline Intra-abdominal & $793(53.5)$ & $779(55.6)$ & $14(17.7)$ & \\
\hline Other regions & $404(27.3)$ & $387(27.6)$ & $17(21.5)$ & \\
\hline Surgical complexity* & & & & $<0.001$ \\
\hline Minor & $253(17.1)$ & $216(15.4)$ & $37(46.8)$ & \\
\hline Moderate & $989(66.8)$ & $962(68.6)$ & $27(34.2)$ & \\
\hline Major & $231(15.6)$ & $216(15.4)$ & $15(19.0)$ & \\
\hline Major + & $8(0.5)$ & $8(0.6)$ & $0(0.0)$ & \\
\hline Type of anesthesia & & & & 0.123 \\
\hline General anesthesia & 1,429 (96.5) & $1,352(96.4)$ & 77 (97.5) & \\
\hline Regional anesthesia & $37(2.5)$ & $35(2.5)$ & $2(2.5)$ & \\
\hline MAC & $15(1.0)$ & $15(1.1)$ & $0(0.0)$ & \\
\hline Main anesthetic agent in general anesthesia & & & & $<0.001$ \\
\hline Desflurane & $780(52.7)$ & $758(54.1)$ & $22(27.8)$ & \\
\hline Sevoflurane & $598(40.4)$ & $547(39.0)$ & $51(64.6)$ & \\
\hline Propofol & $51(3.4)$ & $47(3.4)$ & $4(5.1)$ & \\
\hline Duration (min) & $116.0 \pm 96.0$ & $114.0 \pm 95.0$ & $148.0 \pm 95.0$ & $<0.001$ \\
\hline$\leq 120$ & $1,042(70.4)$ & $1,001(71.4)$ & $41(51.9)$ & $<0.001$ \\
\hline$>120$ & 439 (29.6) & 401 (28.6) & 38 (48.1) & \\
\hline Net fluid balance (ml/min) & $6.0 \pm 55.8$ & $6.1 \pm 57.3$ & $4.3 \pm 5.0$ & 0.712 \\
\hline Transfusion & & & & $<0.001$ \\
\hline No & $1,370(92.5)$ & 1,309 (93.4) & $61(77.2)$ & \\
\hline Yes & $111(7.5)$ & $93(6.6)$ & $18(22.8)$ & \\
\hline Inotropics & & & & $<0.001$ \\
\hline No & 1,176 (79.4) & $1,134(80.9)$ & $42(53.2)$ & \\
\hline Yes & 305 (20.6) & $268(19.1)$ & $37(46.8)$ & \\
\hline PCA & & & & 0.005 \\
\hline No & $863(58.3)$ & $805(57.4)$ & $58(73.4)$ & \\
\hline Yes & $618(41.7)$ & $597(42.6)$ & $21(26.6)$ & \\
\hline Commencement of operation & & & & 0.751 \\
\hline Working time & $818(55.2)$ & $773(55.1)$ & $45(57.0)$ & \\
\hline Other & $663(44.8)$ & $629(44.9)$ & $34(43.0)$ & \\
\hline
\end{tabular}

(Continued to the next page) 
Table 1. Continued

\begin{tabular}{|c|c|c|c|c|}
\hline Variable & Overall $(n=1,481)$ & Group $O(n=1,402)$ & Group R ( $\mathrm{n}=79)$ & P value \\
\hline Origin & & & & $<0.001$ \\
\hline ER & $603(40.7)$ & $588(41.9)$ & $15(19.0)$ & \\
\hline ICU & $117(7.9)$ & $85(6.1)$ & $32(40.5)$ & \\
\hline Ward & 761 (51.4) & $729(52.0)$ & $32(40.5)$ & \\
\hline Destination & & & & $<0.001$ \\
\hline ICU & 383 (25.9) & 335 (23.9) & $48(60.8)$ & \\
\hline Ward & $1,098(74.1)$ & 1,067 (76.1) & $31(39.2)$ & \\
\hline
\end{tabular}

Values are presented as number (\%) or mean \pm SD. Group 0: patients who underwent emergency operations without a previous operation, Group R: patients who underwent emergency reoperations following a previous operation within 60 days. ASA: American Society of Anesthesiologists, MAC: monitoring anesthesia care, PCA: patient-controlled analgesia, ER: emergency room, ICU: intensive care unit. *Surgical complexity: minor, moderate, major, and major. + blood loss $\leq 100,101-500,501-999$, and 1,000 ml. P values for differences were determined by using the chi-squares, Fisher's exact test, $t$-test, or the Wilcoxon rank-sum test.

Table 2. Top 10 Primary Diagnoses in Emergency Operations and Reoperations

\begin{tabular}{|c|c|c|c|c|}
\hline \multirow{2}{*}{ No. } & \multicolumn{2}{|c|}{ Group $0 *(n=1,402)$} & \multicolumn{2}{|c|}{ Group $R^{\dagger}(n=79)$} \\
\hline & Diagnosis & Number (\%) & Diagnosis & Number (\%) \\
\hline 1 & Appendicitis & 249 (17.8) & $\mathrm{SAH}$ & $10(12.7)$ \\
\hline 2 & Cholecystitis & $219(15.6)$ & $\mathrm{ICH}$ & $9(11.4)$ \\
\hline 3 & Fracture & $212(15.1)$ & $\mathrm{SDH}$ & $7(8.9)$ \\
\hline 4 & Pregnancy & $119(8.5)$ & EDH & $5(6.3)$ \\
\hline 5 & $\mathrm{SDH}$ & 79 (5.6) & Tonsillitis & $5(6.3)$ \\
\hline 6 & Ovary cyst torsion & $42(3.0)$ & Deep neck infection & $3(3.8)$ \\
\hline 7 & $\mathrm{ICH}$ & $41(2.9)$ & Pyogenic arthritis & $3(3.8)$ \\
\hline 8 & $\mathrm{SAH}$ & $29(2.1)$ & Uterine cancer & $3(3.8)$ \\
\hline 9 & Cerebral infarct & $28(2.0)$ & Thyroid cancer & $2(2.5)$ \\
\hline 10 & Pneumothorax & $24(1.7)$ & Ectopic pregnancy & $2(2.5)$ \\
\hline
\end{tabular}

SDH: subdural hematoma, ICH: intracerebral hemorrhage, SAH: subarachnoidal hemorrhage, EDH: epidural hematoma. *Patients who underwent emergency operations without a previous operation, ${ }^{\dagger}$ Patients who underwent emergency reoperations following a previous operation within 60 days.

The mean age of the study subjects was $51.0 \pm 19.2$ years and 668 (45.1\%) were male. Age, American Society of Anesthesiology classification, operator, lesion, surgical complexity, the main anesthetic agent in general anesthesia, the duration of anesthesia, transfusions, inotropics, PCA, origin, and destination were significantly different between Group O and Group R (Table 1).

The diagnoses in Group O were appendicitis (249 [17.8\%]), followed by cholecystitis (219 [15.6\%]), fracture (212 [15.1\%]), and pregnancy (119 [8.5\%]) (Table 2). The most common disease categories in Group R were subarachnoidal hemorrhage (10 [12.7\%]), followed by intracerebral hemorrhage (9 [11.4\%]), and subdural hematoma (7 [8.9\%]) (Table 2). The most common surgeries performed in Group $\mathrm{O}$ were appendectomy (251 [17.9\%]), followed by cholecystectomy (222 [15.8\%]), open reduction and internal fixation (130 [9.3\%]), and Cesarean section (119 [8.5\%]) (Table 3). The previous surgeries in Group R were extraventricular drainage (14 [17.7\%]), craniec- tomy (11 $[13.9 \%])$, tonsillectomy (6 [7.6\%]), and craniotomy (4 [5.1\%]) (Table 3).

The most common cause of emergency reoperation was hemorrhage in $42(53.2 \%)$ cases, followed by infection or sepsis in 11 (13.9\%) cases, wound dehiscence in seven $(8.8 \%)$, and increased intracranial pressure in four $(5.1 \%)$ patients. Sixty-four $(4.3 \%)$ of the 1,481 patients died within 30 days postoperatively. Mortality was observed in $16.5 \%$ $(13 / 79)$ in Group R. Death occurred in 11 patients after neurosurgery and in two patients after general surgery in Group R. The fatality rate associated with each cause of reoperation ranged from $0 \%$ to $36.4 \%$ (Table 4 ).

Multivariate analysis revealed that intracranial (odds ratio $[\mathrm{OR}]=6.32, \mathrm{P}<0.001)$ and intraoral $(\mathrm{OR}=28.37, \mathrm{P}<$ 0.001 ) lesions were significantly associated with emergency reoperation. The highest MAP $\geq 110 \mathrm{mmHg}$ was significantly correlated with emergency reoperation compared to $\mathrm{MAP}<110 \mathrm{mmHg}(\mathrm{OR}=1.76, \mathrm{P}=0.040)$. The highest HR 
Table 3. Surgical Procedures in Group 0 and Previous Operations in Group R

\begin{tabular}{|c|c|c|c|c|}
\hline \multirow{2}{*}{ No. } & \multicolumn{2}{|c|}{ Group $0 *(n=1,402)$} & \multicolumn{2}{|l|}{ Group $R^{\dagger}(n=79)$} \\
\hline & Surgery & Number (\%) & Surgery & Number (\%) \\
\hline 1 & Appendectomy & $251(17.9)$ & EVD & $14(17.7)$ \\
\hline 2 & Cholecystectomy & $222(15.8)$ & Craniectomy & $11(13.9)$ \\
\hline 3 & OR\&IF & $130(9.3)$ & Tonsillectomy & $6(7.6)$ \\
\hline 4 & Cesarean section & 119 (8.5) & Craniotomy & $4(5.1)$ \\
\hline 5 & CR\&IF & $59(4.2)$ & Debridement & $4(5.1)$ \\
\hline 6 & Ovary cystectomy & $45(3.2)$ & OR\&IF & $2(2.5)$ \\
\hline 7 & Burr hole trephination & $42(3.0)$ & Burr hole trephination & $2(2.5)$ \\
\hline 8 & EVD & $41(2.9)$ & Navigation guided removal of intracranial hematoma & $2(2.5)$ \\
\hline 9 & Craniectomy & $40(2.9)$ & Oophorectomy & $2(2.5)$ \\
\hline 10 & Tenorrhaphy & $32(2.3)$ & Salpingectomy & $2(2.5)$ \\
\hline
\end{tabular}

OR\&IF: open reduction and internal fixation, CR\&IF: closed reduction and internal fixation, EVD: extraventricular drainage. *Patients who underwent emergency operations without a previous operation, ${ }^{\dagger}$ Patients who underwent emergency reoperations following a previous operation within 60 days.

Table 4. Causes of Emergency Reoperation and Mortality Rates

\begin{tabular}{lcc}
\hline Causes & $\begin{array}{c}\text { Emergency } \\
\text { reoperation } \\
(\mathrm{n}=79)\end{array}$ & Mortality rate* \\
\hline Hemorrhage & $42(53.2)$ & $6(14.3)$ \\
Infection or Sepsis & $11(13.9)$ & $1(9.1)$ \\
Wound dehiscence & $7(8.8)$ & $1(14.3)$ \\
Increased intracranial pressure & $4(5.1)$ & $1(25.0)$ \\
Thrombotic artery occlusion & $2(2.5)$ & $0(0)$ \\
lleus $_{\text {Others }}^{\dagger}$ & $2(2.5)$ & $0(0)$ \\
\hline
\end{tabular}

Values are presented as number (\%) of categorical variables. *The parentheses include the mortality percentage calculated from each cause of emergency reoperation, ${ }^{\dagger}$ Others include airway obstruction, cerebellar infarction, cerebrospinal fluid leakage, hardware loosening, hygroma, intestinal anastomosis leakage, nerve injury, nonunion, pharyngocutaneous fistula, tracheostoma, and ureteral injury. Among the other causes, airway obstruction, cerebellar infarction, cerebrospinal fluid leakage, and intestinal anastomosis leakage resulted in death.

$\geq 100$ beats/min was significantly correlated with emergency reoperation compared to $\mathrm{HR}<100$ beats/min (OR $=2.87, \mathrm{P}<0.001)$. Hemoglobin levels $<13 \mathrm{~g} / \mathrm{dl}$ in males and $<12 \mathrm{~g} / \mathrm{dl}$ in females were significantly correlated with reoperation $(\mathrm{OR}=2.47, \mathrm{P}=0.001)$. Duration of surgery over two hours was significantly related to reoperation (OR $=1.94, \mathrm{P}=0.025)$. The number of patients treated in the intensive care unit $(\mathrm{ICU})(\mathrm{OR}=2.89, \mathrm{P}=0.007)$ remained statistically significant (Table 5).

\section{DISCUSSION}

Emergency reoperation has been reported to have distinguishing features and risks. Therefore, we investigated the clinical features, as well as anesthetic considerations, of emergency reoperation compared to ordinary emergency operations. In the present study, the factors related to emergency reoperation were intracranial and intraoral lesions, MAP $\geq$ $110 \mathrm{mmHg}$ and $\mathrm{HR} \geq 100$ beats/min before surgery, anemia, duration of operation $>2 \mathrm{~h}$, and ICU stay before the operation.

Emergency reoperation was defined as surgery performed due to a primary surgical condition [10]. The term "reoperation" refers to operations performed within two months of the primary operation and related to the initial surgery [2], although most commonly they were conducted much earlier [6]. In a previous study, reoperations were conducted from postoperative day 1 to day 24 [6]. In contrast, in our investigation, the reoperation period ranged from 0 to 29 days.

Published data related to the incidence of reoperation vary between different populations, with reported rates ranging from $2 \%$ to $21 \%$ according to the definition used, institutional bias, the departments, pathology and operation type, and the presence of coexisting problems $[1,3,11-$ 13]. The incidence of emergency reoperations in this study $(0.83 \%)$ was lower than previous reports because our study included a variety of operations with low potential for reoperation. Lee et al. [14] reported that $2 \%$ of all emergency operations required emergency reoperation within a week, similar to the present report. The reoperation rate in vascular surgery was reported to be $12 \%$ [11]. The incidence of complications requiring emergency re-laparotomy was reported at $1-4.4 \%$ in patients who underwent abdominal surgeries $[2,4,5,15]$. Significant associations between emergency reoperations and male sex have been established 
Table 5. Multivariate Logistic Regression Analyses of Factors Associated with Reoperations $(n=1,481)$

\begin{tabular}{|c|c|c|c|c|}
\hline Variable & Crude odds ratios (95\% Cl) & $P$ value & Adjusted odds ratios (95\% Cl) & $P$ value \\
\hline \multicolumn{5}{|l|}{ Lesion } \\
\hline Intracranial & $4.22(2.31-7.68)$ & $<0.001$ & $6.32(2.41-16.58)$ & $<0.001$ \\
\hline Intraoral & 31.98 (8.30-123.20) & $<0.001$ & $28.37(6.26-128.62)$ & $<0.001$ \\
\hline Cervical & $10.71(3.89-29.48)$ & $<0.001$ & $2.07(0.62-6.93)$ & 0.238 \\
\hline Intrathoracic & $0.35(0.02-6.25)$ & 0.477 & $1.06(0.05-22.83)$ & 0.920 \\
\hline Intra-abdominal & $0.41(0.20-0.84)$ & 0.014 & $1.50(0.64-3.56)$ & 0.354 \\
\hline Others & Reference & & Reference & \\
\hline \multicolumn{5}{|l|}{ Surgical complexity } \\
\hline Minor & $2.95(0.14-61.87)$ & 0.487 & $17.23(0.72-413.69)$ & 0.079 \\
\hline Moderate & $0.49(0.02-10.24)$ & 0.643 & $2.71(0.12-61.46)$ & 0.531 \\
\hline Major & $1.22(0.06-26.19)$ & 0.900 & $1.57(0.07-36.91)$ & 0.779 \\
\hline Major + & Reference & & Reference & \\
\hline \multicolumn{5}{|l|}{ Highest MAP } \\
\hline$<110$ & Reference & & Reference & \\
\hline$\geq 110$ & $3.19(2.01-5.04)$ & $<0.001$ & $1.76(1.03-3.03)$ & 0.040 \\
\hline \multicolumn{5}{|l|}{ Highest HR } \\
\hline$<100$ & Reference & & Reference & \\
\hline$\geq 100$ & $6.21(3.91-9.87)$ & $<0.001$ & $2.87(1.64-5.02)$ & $<0.001$ \\
\hline \multicolumn{5}{|l|}{$\mathrm{Hgb}(\mathrm{g} / \mathrm{dl})$} \\
\hline Male $<13$, female $<12$ & 3.18 (1.99-5.07) & $<0.001$ & Reference & \\
\hline Male $\geq 13$, female $\geq 12$ & Reference & & $2.47(1.44-4.27)$ & 0.001 \\
\hline \multicolumn{5}{|l|}{ Duration (min) } \\
\hline$\leq 120$ & Reference & & Reference & \\
\hline$>120$ & $2.31(1.47-3.64)$ & $<0.001$ & 1.94 (1.09-3.46) & 0.025 \\
\hline \multicolumn{5}{|l|}{ Origin } \\
\hline ER & $0.59(0.32-1.09)$ & 0.094 & $0.48(0.23-1.01)$ & 0.052 \\
\hline ICU & 8.53 (4.99-14.59) & $<0.001$ & $2.89(1.34-6.23)$ & 0.007 \\
\hline Ward & Reference & & Reference & \\
\hline
\end{tabular}

A multivariate logistic regression model was constructed using stepwise selection (with entry criteria of $P<0.1$ and significant criteria of $P<$ 0.05). Cl: confidence interval, MAP: mean arterial pressure, HR: heart rate, Hgb: hemoglobin, ER: emergency room, ICU: intensive care unit.

$[3,12]$. The relative paucity of males in our study differs from other studies and suggests the inherent effects of the hospital and region.

One of the most important factors affecting mortality rates in emergency reoperations is the cause, lesion, and organ involved in the reoperation [2]. The 30-day mortality rate for emergency abdominal reoperations was reported to range from $5.5 \%$ to $48 \%[1,3,6]$. Hemorrhage and infection, as well as leakage from intestinal repair sites, were associated with low, mid, and high mortality risks in intra-abdominal operations, respectively [2]. The overall mortality rate in patients undergoing vascular surgery was $16 \%$ [11]. In contrast, in our study, the mortality among re-operated patients was $16.5 \%$ (13/79). A comparison of the incidence with previous reports was difficult because of the different methodologies used to calculate the incidence and variation in the populations included. Reoperation is riskier, even though patients are likely to respond positively to perioperative medical treatment [2]. Other risk factors for mortality reported in a previous study included hypoproteinemia, a delay in diagnosis, and intestinal obstruction [1].

Causes of urgent abdominal re-explorations were known to involve leakage from the intestinal repair site, hemorrhage, intestinal perforation, intra-abdominal infection or sepsis, mechanical obstruction, intestinal necrosis, enteral anastomosis failure, stomal complications, surgical wound dehiscence, fistulas, and ileus $[1,2]$. Intracranial lesions show an increased tendency for emergency reoperation [7], consistent with our findings. The fact that six patients died from intracranial hemorrhage also suggests the importance of brain lesions in the increased risk of reoperation. Neurosurgical reoperations tend to be performed frequently following the initial operation [2,10]. Surgical complexity was reportedly associated with emergency reoperations [3], which was not shown in our findings.

In our study, the highest MAP $\geq 110 \mathrm{mmHg}$ and the 
highest HR $\geq 100$ beats/min were related to emergency reoperations, which indirectly reflected high hemodynamic instability. Hypertension may be due to Cushing reflex in intracranial problems, the use of inotropics, and psychological stress. Shock and hemorrhage requiring blood transfusion increase patients' susceptibility to postoperative mortality in emergency surgeries [9]. Tachycardia is common in these patients and suggests unstable intravascular volume $[1,6]$. These patients are usually anemic [1]. A lower hemoglobin concentration is associated with a higher risk of reoperation [10], consistent with our findings, indirectly suggesting coagulation deficiency and poor nutrition. If hemorrhage is associated with severe anemia or severe hypotension, the mortality rate increases proportionately [16].

The possibility of effectively lowering the mortality rate depends on the success of the first operation [1,2]. Therefore, a number of these problems can be avoided by taking all precautions possible at the time of the initial operation to minimize the occurrence of complications [1]. For example, a majority of the hemorrhages were caused by technical errors, such as inadequate hemostasis during the first operation [2]. Surgical challenges include inappropriate judgment, poorly developed skills, and incorrect handling of surgical devices [16]. Half of the reoperations were minor surgeries in the present study, suggesting possible technical errors during the initial operation. In our study, patients undergoing emergency reoperations were mostly transferred from the ICU. This reflects the urgency of most reoperation cases and the grave physical status of these patients.

This study had several limitations. First, our research was limited by the size of the study groups. This study was based on data obtained from a single institution and surgeries of short duration (70.0\% were less than two hours) and involved minor-to-moderate types of surgery (83.9\%). Therefore, the results may differ from those involving larger populations and multiple institutions, such as regional emergency trauma centers. Our institution is a university-affiliated community hospital. Institutional factors may limit generalizability. Second, the variables in our investigation may be too diverse to perform a comprehensive analysis and exclude the role of unmeasured variables. The variety of diseases and operations included did not allow a clear distinction between the effects of reoperation on patient outcomes. The results should be based on analyses according to individual departments and procedures in the future. The selection of abnormal variables, including vital signs, was defined arbitrarily and these aspects may have affected our results. Third, we could not analyze the anesthetic implications for postoperative mortality as an endpoint due to the small number of mortalities. Lastly, variations in surgical procedures due to the surgeon's experience, operative devices, and methods could not be analyzed in a meaningful way and were beyond the scope of the study.

In summary, our results described the clinical features of emergency reoperations. The factors associated with a higher proportion of emergency reoperations were intracranial and intraoral lesions, highest MAP $\geq 110 \mathrm{mmHg}$ and $H R \geq 100$ beats/min, anemia, and arrival from the ICU. Emergency anesthesia is an important segment of clinical anesthesiology and advances in anesthetic care affect mortality. Particular attention must be paid to emergency reoperation and more time and resources are required to redefine the clinical features of emergency reoperation.

\section{CONFLICTS OF INTEREST}

No potential conflict of interest relevant to this article was reported.

\section{AUTHOR CONTRIBUTIONS}

Conceptualization: Jun Rho Yoon. Data acquisition: Jun Rho Yoon, Kyoung Rim Kim, Taehee Kim. Formal analysis: Tae Kwan Kim. Funding: Ui Jin Park. Supervision: Jun Rho Yoon. Writing_original draft: Jun Rho Yoon. Writing-review \& editing: Yu Na Choi, Tae Kwan Kim.

\section{ORCID}

Tae Kwan Kim, https://orcid.org/0000-0002-0635-3304 Jun Rho Yoon, https://orcid.org/0000-0001-7457-7433 Yu Na Choi, https://orcid.org/0000-0001-9111-8298 Ui Jin Park, https://orcid.org/0000-0003-2114-0195 Kyoung Rim Kim, https://orcid.org/0000-0001-5442-8705 Taehee Kim, https://orcid.org/0000-0002-0476-3254

\section{REFERENCES}

1. Wain MO, Sykes PA. Emergency abdominal re-exploration in a district general hospital. Ann R Coll Surg Engl 1987; 69: 169-74. 
2. Unalp HR, Kamer E, Kar H, Bal A, Peskersoy M, Ali Onal M. Urgent abdominal re-explorations. World J Emerg Surg 2006; 1: 10.

3. Guevara OA, Rubio-Romero JA, Ruiz-Parra AI. Unplanned reoperations: is emergency surgery a risk factor? A cohort study. J Surg Res 2013; 182: 11-6.

4. Tera H, Aberg C. Relaparotomy. A ten-year series. Acta Chir Scand 1975; 141: 637-44

5. O'Leary DP, Hardwick RH, Cosford E, Knox AJ. Does hospital mortality rate reflect quality of care on a surgical unit? Ann R Coll Surg Engl 1997; 79: 46-8.

6. Harbrecht PJ, Garrison RN, Fry DE. Early urgent relaparotomy. Arch Surg 1984; 119: 369-74.

7. Copeland GP. The POSSUM system of surgical audit. Arch Surg 2002; 137: 15-9.

8. Donati A, Ruzzi M, Adrario E, Pelaia P, Coluzzi F, Gabbanelli V, et al. A new and feasible model for predicting operative risk. Br J Anaesth 2004; 93: 393-9.

9. Matsuyama T, Iranami H, Fujii K, Inoue M, Nakagawa R, Kawashima K. Risk factors for postoperative mortality and morbidities in emergency surgeries. J Anesth 2013; 27: 838-43.

10. Kwinta BM, Krzyżewski RM, Kliś KM, Donicz P, Gackowska M,
Polak J, et al. Emergency reoperations in cranial neurosurgery. World Neurosurg 2017; 105: 749-54.

11. Davies AH, Pope I, Collin J, Morris PJ. Early reoperation after major vascular surgery: a four-year prospective analysis. Br J Surg 1992; 79: 76-8.

12. Brant JA, Bur AM, Chai R, Hatten K, Nicolli EA, Fischer JP, et al. Reoperation following adult tonsillectomy: review of the American College of Surgeons National Surgical Quality Improvement Program. Otolaryngol Head Neck Surg 2016; 154: 779-84.

13. Ramachandran R, Hegde T. Chronic subdural hematomas--causes of morbidity and mortality. Surg Neurol 2007; 67: 367-72.

14. Lee DI, Lee MH, Shin OY, Shin KY. A clinical study of anesthesia for emergency surgery. Korean J Anesthesiol 1979; 12: 252-60.

15. Ching SS, Muralikrishnan VP, Whiteley GS. Relaparotomy: a fiveyear review of indications and outcome. Int J Clin Pract 2003; 57: 333-7.

16. Irita K. Risk and crisis management in intraoperative hemorrhage: human factors in hemorrhagic critical events. Korean J Anesthesiol 2011; 60: 151-60. 